\title{
Effects on carrion consumption in a mammalian scavenger community when dominant species are excluded
}

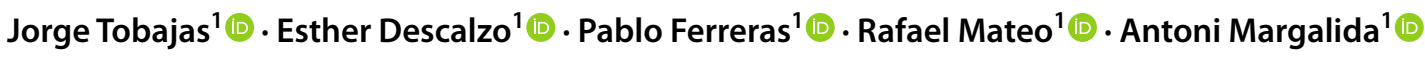

Received: 1 February 2021 / Accepted: 22 July 2021 / Published online: 17 August 2021

(c) The Author(s) 2021

\begin{abstract}
Carrion is a valuable resource exploited not only by obligate scavengers but also by a wide variety of facultative scavengers. These species provide several important ecosystem services which can suffer if the scavenger community composition is altered, thus reducing the ecosystem provided. We studied the response of the Mediterranean facultative scavenger community to the exclusion of larger scavenger species (red fox Vulpes vulpes, European badger Meles meles, and wild boar Sus scrofa) using an exclusion fence permeable to small scavenger species (mainly Egyptian mongoose Herpestes ichneumon, common genet Genetta genetta, and stone marten Martes foina). The exclusion of dominant facultative scavengers led to a significant reduction in the amount of carrion consumed and an increase in carrion available for smaller species and decomposers, over a longer period of time. Although carrion consumption by the non-excluded species increased inside the exclusion area relative to the control area, it was insufficient to compensate for the carrion not eaten by the dominant scavengers. Of the small scavenger species, only the Egyptian mongoose significantly increased its carrion consumption in the exclusion area, and was the main beneficiary of the exclusion of dominant facultative scavengers. Therefore, altering the facultative scavenger community in Mediterranean woodlands can reduce the efficiency of small carcass removal and benefit other opportunistic species, such as the Egyptian mongoose, by increasing the carrion available to them. This interaction could have substantial implications for disease transmission, nutrient cycling, and ecosystem function.
\end{abstract}

Keywords Carrion ecology $\cdot$ Competition $\cdot$ Food webs $\cdot$ Mesocarnivores $\cdot$ Scavenging patterns

\section{Introduction}

Scavenging plays an important role in the maintenance of ecological processes, affecting species assemblages and ecosystem function (Ogada et al. 2012; DeVault et al. 2016; Sebastián-González et al. 2016). In addition, scavengers provide important supporting, regulatory, and cultural ecosystem services (Moleón et al. 2014; DeVault et al. 2016). For example, the elimination of carrion by scavengers can reduce the probability of disease transmission (Markandya et al. 2008; Ogada et al. 2012; Vidal et al. 2013), enhance redistribution and energy transfer pathways within an

Handling editor: Adriano Martinoli.

Jorge Tobajas

jtobajas47@gmail.com

1 Instituto de Investigación en Recursos Cinegéticos (IREC), CSIC-UCLM-JCCM, Ronda de Toledo no 12, 13071 Ciudad Real, Spain ecosystem (DeVault et al. 2003, 2011), regulate the negative ecological impacts of some species that can use subsidiary food sources (Butler and du Toit 2002; Oro et al. 2013), or reduce the need for human management of carrion resulting from livestock production and hunting activities (Margalida et al. 2011; Margalida and Colomer 2012; Mateo-Tomás et al. 2015). It is therefore necessary to understand the relationships within, and functions of, scavenger communities, and how changes in these communities can affect their overall scavenging efficiency.

The extirpation of top predators and the cessation of persecution of mesocarnivores as a result of their legal protection have triggered the growth of mesocarnivore populations in many areas (Reynolds and Tapper 1996; Moreno-Opo et al. 2015; Jimenez et al. 2019). The lack of apex predators has allowed an increase in facultative scavengers such as red fox Vulpes vulpes, European badger Meles meles, and wild boar Sus scrofa that can dominate carrion use through their significant body-size and adaptations to find and use carrion efficiently (Butler and du Toit 2002; Stiegler et al. 
2020; Tobajas et al. (in press). In addition to this, the continued increase of landscape fragmentation and agricultural encroachment tends to favor more adaptable species and has led to the dominance of abundant generalist mesopredator species (Swihart et al. 2003; Carricondo-Sanchez et al. 2016; Jahren et al. 2020; Tobajas et al. (in press). Despite the importance of scavengers for ecosystem services and human health, very little is known about the interactions between mammalian scavenger species in Mediterranean ecosystems (Sebastián-González et al. 2013, 2016; PardoBarquín et al. 2019). Research is therefore needed to explore mammalian scavenger communities and their interactions, with special emphasis on the roles that key species play in human-altered landscapes (Carricondo-Sanchez et al. 2016; Jahren et al. 2020).

The competitive interactions between scavenger species depend on several factors related to scavenger type (i.e. avian vs mammalian), habitat (Sebastián-González et al. 2013; Turner et al. 2017; Pardo-Barquín et al. 2019), activity patterns (DeVault and Rhodes 2002; Carrasco-Garcia et al. 2018), scavenging efficiencies (Moreno-Opo et al. 2016; Tobajas et al. (in press), carcass types (Moreno-Opo et al. 2015; Turner et al. 2017), season Tobajas et al. (in press), and body-size ratios (Butler and du Toit 2002; Amorós et al. 2020). In the case of competition between vultures and mammalian scavengers, habitat determines their relative efficiency of carrion exploitation (Pardo-Barquín et al. 2019); vultures are highly efficient at carcass location in open areas (Ogada et al. 2012; Hill et al. 2018), but limited in their carcass detection abilities in forested areas (DeVault and Rhodes 2002; Stiegler et al. 2020). Therefore, competition for carrion in woodland areas is generally between ground dwelling, mammalian facultative scavengers, with dominance in carcass usage being determined by their respective body-sizes, scavenging efficiencies, and activity patterns, as well as by weather conditions (DeVault and Rhodes 2002; Butler and du Toit 2002; Carrasco-Garcia et al. 2018; Tobajas et al. (in press). When vultures are absent, mammalian scavengers can increase their carrion consumption and abundance (Ogada et al. 2012; Morales-Reyes et al. 2017; Cunningham et al. 2018). However, mammals take longer to detect and consume carcasses than vultures and the proportion of carcasses not located or consumed by vertebrates increases (Olson et al. 2012; Hill et al. 2018), reducing the efficiency of the ecosystem services provided by the scavenger guild. Nonetheless, the detailed effects of modifications to the mammalian scavenger community are still understudied (Olson et al. 2012; Cunningham et al. 2018; Hill et al. 2018), particularly regarding the roles of, and interactions between, the main scavenger species of Mediterranean ecosystems (Sebastián-González et al. 2016).
The aim of this study was to evaluate the response of the mammalian facultative scavenger community in Mediterranean woodland ecosystems to the exclusion of the larger, dominant scavenger species from access to carcasses, using fences permeable only to small species. To this end, we experimentally placed rabbit carcasses inside and outside a fenced plot in a Mediterranean woodland area and used camera-traps to record the foraging activity of mammalian scavengers. We predicted that when dominant facultative scavengers were excluded from carcasses, there would be: (1) a decrease in the scavenging efficiency of the scavenger community, increasing the time from carcass placement to their fully consumption (the persistence time) and the number of carcasses not fully eaten; (2) an increase in the scavenging activity of smaller, subordinate facultative scavenger species; and (3) that other singular opportunistic species would be favored by the removal of larger dominant scavengers.

\section{Methods}

\section{Study area}

The study was carried out in the Picón municipality $\left(4^{\circ} 5^{\prime} 0^{\prime \prime} \mathrm{W}, 39^{\circ} 5^{\prime} 0^{\prime \prime} \mathrm{N}\right)$ in Ciudad Real province, central Spain (Fig. 1). The vegetation of the landscape is characterized by a mixture of Mediterranean scrubland (dominated by holm oak Quercus ilex rotundifolia and crimson-spot rockrose Cistus ladanifer, wild olive trees Olea europaea silvestris), surrounded by agricultural olive orchards and cereal fields. The climate is Mediterranean, with wet and mild winters and dry and hot summers. The human presence in the area is related to agricultural activities and to seasonal hunting activity in winter. At least ten years before our study, a semipermeable fenced plot was built inside the study area by local hunters as part of a rabbit population recovery program involving reintroduced rabbits (see Descalzo et al. 2021). The fencing provided a safe area to reduce rabbit predation by mesocarnivores during the first days after their release, when they are most vulnerable (Moreno et al. 2004; Tobajas et al. 2020a). Our study area therefore comprised two parts, the fenced exclusion area and the control area consisting of three plots surrounding the fenced plot with and approximate monitored area of 74 ha. The exclusion area consisted of a 0.42 ha plot surrounded by a $1.5 \mathrm{~m}$ high wire netting fence with an $0.85 \mathrm{~m}$ wide outside overhang and passageways under the fence $(66 \mathrm{~cm}$ wide $\times 8 \mathrm{~cm}$ high) originally intended for dispersing rabbits to leave the fenced area and recolonize the surroundings. The mammalian scavenger community in the general study area comprised red fox, Egyptian mongoose Herpestes ichneumon, stone marten Martes foina, 


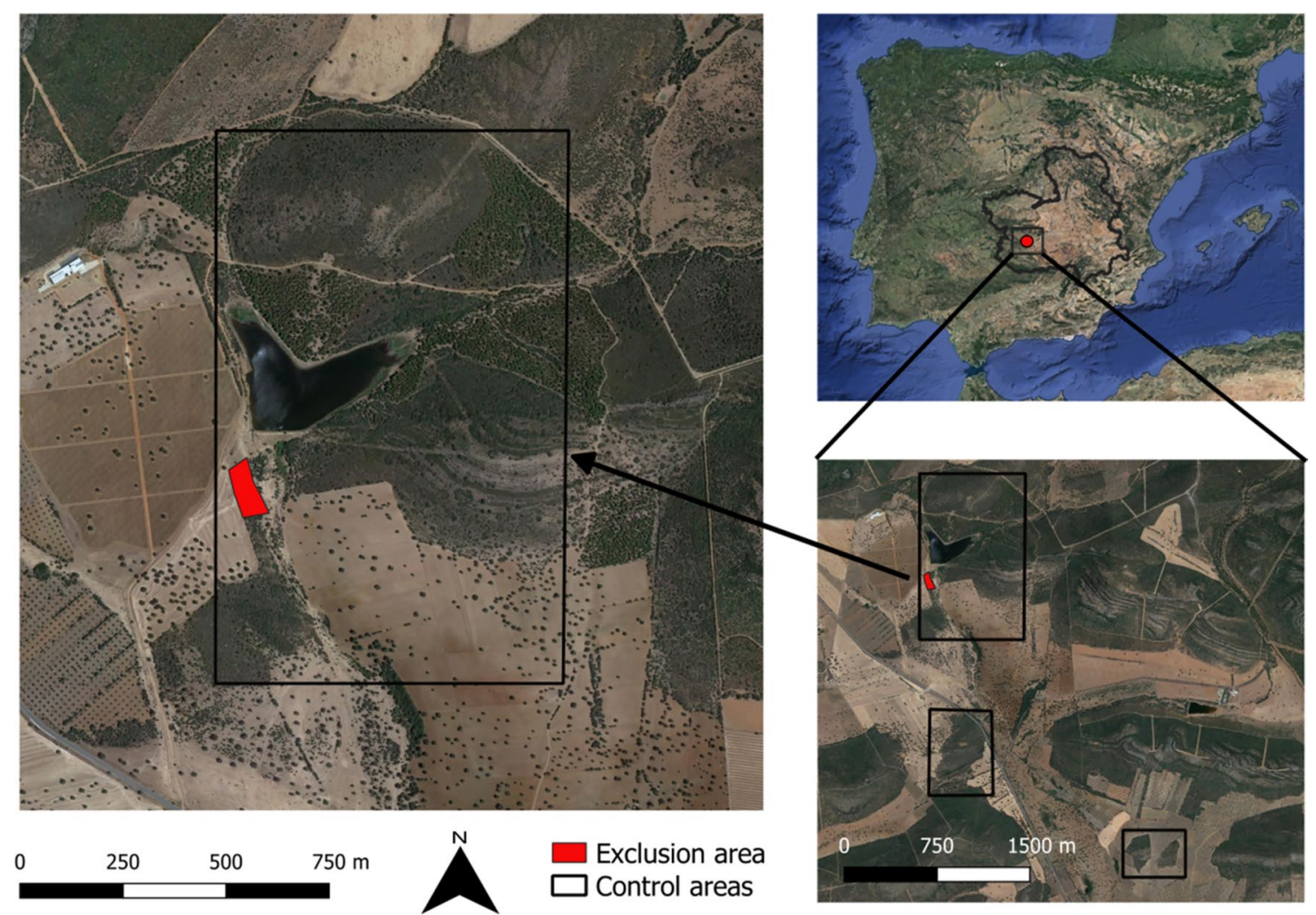

Fig. 1 Map of the study area in the Picón municipality (Castilla-La Mancha, Spain). The control areas consisted in the woodland area within the black squares

European badger, common genet Genetta genetta, weasel Mustela nivalis, and wild boar.

\section{Carcass monitoring}

A total of 412 gutted rabbit carcasses were spread across the exclusion $(n=104)$ and control areas $(n=308)$ between October and April of 2016 and the same period of 2017. The distance between nearest carcasses in the control area ranged between 204-637 $\mathrm{m}$ with an average of $10.62 \pm 3.22$ SD carcasses placed each week, and with between 4 and 14 carcasses placed simultaneously (Fig. 1). Due to the small size of the exclusion area, an average of $3.59 \pm 1.05$ SD carcasses were distributed inside the fenced plot each week, ranging between 1 and 4 carcasses simultaneously. The exclusion area was permeable to small carnivores. The smaller species, such as the Egyptian mongoose, could enter through the underground passageways, while those good at climbing, such as the stone marten and the common genet, could easily scale the exclusion fence. However, the fence was impermeable for larger species such as red fox, European badger, and wild boar.

To document scavenging events, we placed infrared camera-traps (Spartan SR1-BK®, HCO Outdoor Products,
Norcross, Georgia, USA) on trees around 50-60 cm above the ground in front of the wooden stakes to which rabbit carcasses were tied. The carcasses were hidden under loose piles of stones to avoid detection by aerial scavengers and allowing the mammalian scavengers to detect it by the smell. Cameras were programmed to record 10 -s videos with a minimum time delay $(0 \mathrm{~s})$ between consecutive recordings to maximize the number of videos taken per scavenging event. The cameras were active $24 \mathrm{~h}$ /day and were visited approximately every seven days for carcass replacement, cameratrap maintenance, and data download. Carcasses were only left out for seven day periods because insect and microbial activity rapidly depleted the carcasses, reducing the probability of their consumption by mammalian scavengers (DeVault et al. 2004). Carcass consumption was recorded as a binomial value (consumed/not consumed) because the carcasses were either totally consumed or removed by scavengers (at the first scavenging event) as a consequence of their small size. Small mammal and bird species observed at carcasses were not considered in the analysis due the difficulty of obtaining camera evidence of their scavenging activities. Birds normally pecked several times at a carcass before flying off, and were probably eating flies, worms, or very small pieces of carrion. One carcass was completely 
consumed by a Northern goshawk Accipiter gentilis and this was excluded from the analysis.

The camera footage was analyzed to record the species, date, and time of each scavenging event. Camera trap data were used to establish the composition of the scavenger community, the feeding efficiency of each species, and carcass persistence time. We used this data to compare the exclusion and control areas. To determine how the scavenger community utilized the carrion, we calculated the proportion of carcasses consumed by each scavenger species from the total carcasses placed in each area (Table 1). To evaluate carcass persistence, we estimated the carcass consumption time for each carcass as the time in days between carcass placement and its complete consumption by scavengers.

\section{Statistical analyses}

To assess the scavenging efficiency of the facultative scavenger community, and whether the exclusion treatment reduced the total carcass consumption, we used a General Linear Mixed Model (GLMM) with binomial error and logit link function using the carcass consumption (consumed $v s$ not consumed) as a response variable, the treatment area as a factor (exclusion vs control), and each carcass site as a random factor to account for differences among specific locations. To assess the effect of exclusion on carcass consumption by the non-excluded species, we fitted a GLMM with binomial error and logit link function using carcasses consumption from the non-excluded species as a response variable. The treatment area was included as a factor and carcass location as a random factor. At the species level, to assess whether some facultative species were favored by the exclusion of the larger scavengers, we constructed GLMMs with binomial error and logit link function using the carcasses consumption of each non-excluded species as a response variable, the treatment area as a factor, and carcass location as a random factor. Data regarding unidentified scavengers ( $n=3$ carcasses) due to camera failure were not used for the analyses of non-excluded species. The normality of the residuals was checked visually and using the Shapiro-Wilk Normality Test and $Q-Q$ Plots to meet homoscedasticity assumptions. A $p$-value $<0.05$ was used to determine statistical significance for all analyses. All GLMMs were fitted using the "nlme" and "rcompanion" packages with R software version 4.0.0 (R Core Team 2020).

Finally, we used the Kaplan-Meier procedure to compare carcass persistence times in the exclusion and control areas using the R package "survival". We chose this procedure because of the single binary predictor describing carcass removal with time (Hill et al. 2018).

\section{Results}

The proportion of carcasses consumed by vertebrate scavengers was $37.5 \%$ in the exclusion area and $76.9 \%$ in the control area (Table 1). The main scavenger species in the control area were red fox, Egyptian mongoose and European badger, accounting for $23.7 \%, 20.1 \%$ and $17.9 \%$ of consumed carcasses, respectively (Table 1). Other scavenger species with relative importance in control areas was the feral dog (Canis lupus familiaris), consuming more carcasses (5.8\%) than other wild scavengers such as wild boar $(4.6 \%)$ or stone marten (3.6\%) (Table 1). In the exclusion area the main scavengers were the Egyptian mongoose with $31.7 \%$ of consumed carcasses, followed by the stone marten and common genet (2.9\% and $1.9 \%$ respectively; Table 1$)$.

The GLMM models found that the proportion of carcasses consumed within the exclusion area was significantly lower $\left(F_{1,377}=17.23, p<0.001\right)$ than in control areas
Table 1 Consumed carcasses by each scavenger species in the exclusion and control areas, as well as carcass persistence time in days

\begin{tabular}{|c|c|c|c|c|}
\hline \multirow[t]{2}{*}{ Species } & \multicolumn{2}{|c|}{ Exclusion area } & \multicolumn{2}{|c|}{ Control area } \\
\hline & $n$ & $\%$ & $n$ & $\%$ \\
\hline Common genet (Genetta genetta) & 2 & 1.9 & 1 & 0.3 \\
\hline Egyptian mongoose (Herpestes ichneumon) & 33 & 31.7 & 62 & 20.1 \\
\hline European badger (Meles meles) & 0 & 0 & 55 & 17.9 \\
\hline Feral dog (Canis lupus familiaris) & 0 & 0 & 18 & 5.8 \\
\hline Red fox (Vulpes vulpes) & 0 & 0 & 73 & 23.7 \\
\hline Stone marten (Martes foina) & 3 & 2.9 & 11 & 3.6 \\
\hline Weasel (Mustela nivalis) & 1 & 1 & 0 & 0 \\
\hline Wild boar (Sus scrofa) & 0 & 0 & 14 & 4.6 \\
\hline Unidentified & 0 & 0 & 3 & 0.9 \\
\hline Carcasses not consumed & 65 & 62.5 & 71 & 23.1 \\
\hline Total carcasses consumed & 39 & 37.5 & 237 & 76.9 \\
\hline Mean persistence time in days (SE) & \multicolumn{2}{|c|}{$5.40(0.59)$} & \multicolumn{2}{|c|}{$3.75(0.25)$} \\
\hline
\end{tabular}

The standard errors for the persistence time values are shown in brackets 
(Fig. 2), showing a loss of efficiency when the dominant facultative scavengers are excluded. In contrast, the proportion of carcasses consumed by the species not excluded did not differ significantly between the exclusion and control areas $\left(F_{1,374}=2.63, p=0.114\right)$, although it was slightly higher in the exclusion area (0.375) than in the control area (0.246) (Table 1). However, the proportion of carcasses consumed by the Egyptian mongoose was significantly higher in the exclusion area compared to the control area $\left(F_{1,374}=4.38\right.$, $p=0.044$ ), and this species clearly benefited the most from the exclusion of the larger facultative scavengers (Table 1, Fig. 4). In contrast, with respect the proportion of carcasses consumed, no significant differences were found between study areas for the common genet $\left(F_{1,374}=2.90\right.$, $p=0.1)$ and the stone marten $\left(F_{1,374}=0.03, p=0.856\right)$. The Kaplan-Meier survival analysis showed that carcasses persisted for longer within exclusion area $\left(\chi_{1,412}^{2}=43.1\right.$, $p<0.001$ ) compared to the control area (Fig. 3).

\section{Discussion}

Our findings show that exclusion of the larger facultative scavengers reduces the overall efficiency of the scavenger community (Olson et al. 2012; Cunningham et al. 2018), reducing the consumption of carrion by half (Fig. 2). This increase in the proportion of carcasses not consumed in the exclusion area was partially compensated for by the

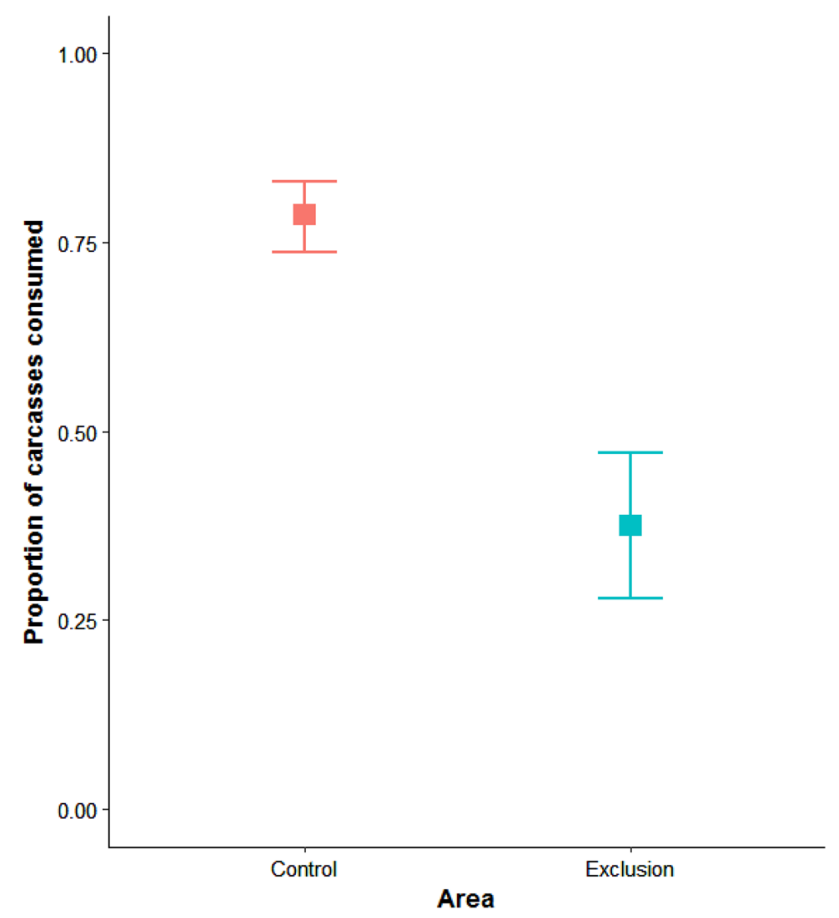

Fig. 2 Mean proportion and 95\% confidence intervals of rabbit carcass consumption in the exclusion and control areas

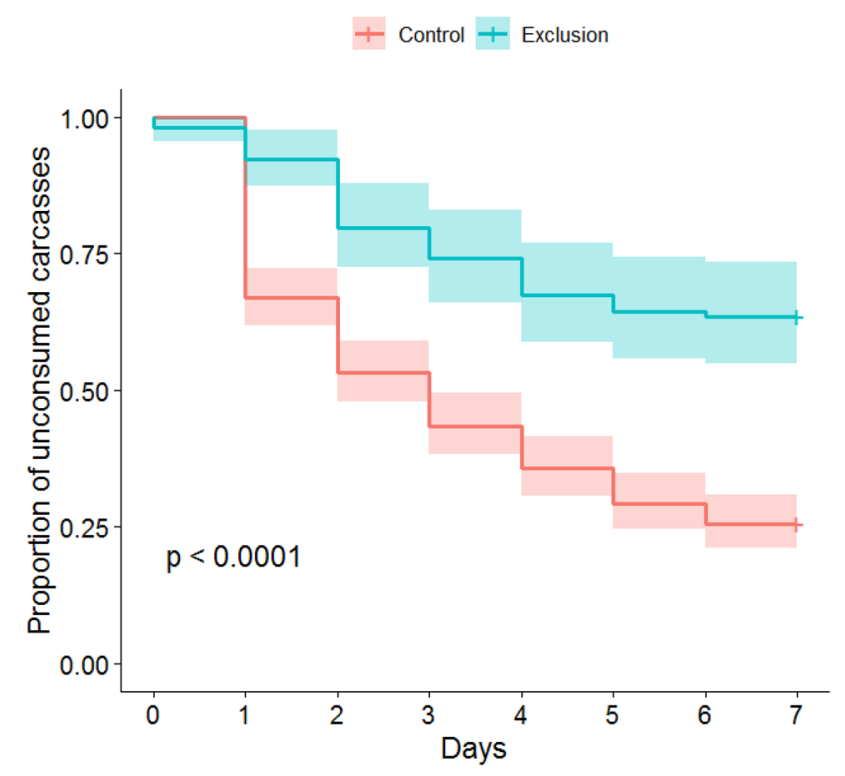

Fig. 3 Proportion of carcasses not consumed within a 7-day period in the exclusion and control areas. Shading shows the 95\% confidence intervals. The $p$-value is from a log-rank test comparing the carcass survival curves

increased activity of smaller species not excluded, mainly by the Egyptian mongoose. Nevertheless, the increased consumption rates of Egyptian mongoose in the exclusion area were not enough to compensate for the loss of efficiency due to the absence of the excluded species

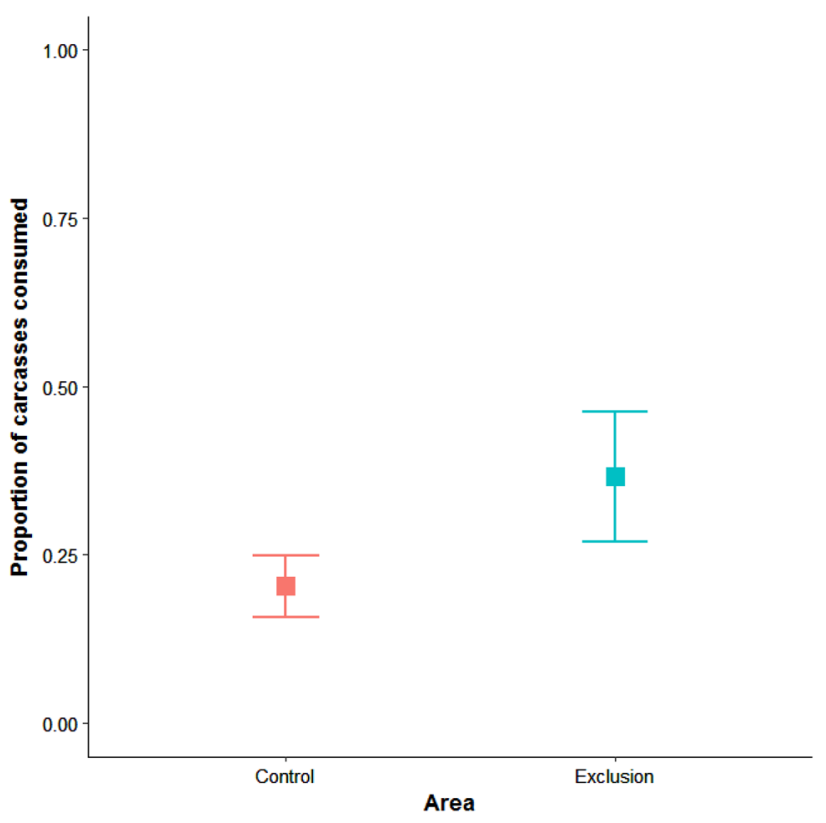

Fig. 4 Mean proportion and 95\% confidence intervals of rabbit carcass consumption by the Egyptian mongoose in the exclusion and control areas 
(Cunningham et al. 2018; Hill et al. 2018). The inability of vultures to effectively utilize carrion in wooded areas probably means that they were unable to offset the reduction in carrion taken by the larger mammalian scavengers (Turner et al. 2020). Therefore, our prediction 1 (that a decrease in scavenging efficiency increases the persistence time and proportion of carcasses not consumed) was supported, but not prediction 2 (that a significant increase would occur in the scavenging activity of the non-excluded mammalian facultative scavenger species).

We expected that the exclusion of dominant scavenger species by body-size would allow other smaller scavengers to expand their spatial and temporal habitat use (Monterroso et al. 2014, 2020; Jimenez et al. 2019), and thus scavenge more carcasses (Cunningham et al. 2018). Also, that the lack of dominant scavengers, and the removal of their monopoly on carcasses, would result in more carrion available for small scavengers (DeVault et al. 2011; Olson et al. 2012; Cunningham et al. 2018). Our results showed that only the Egyptian mongoose significantly increased its carrion consumption in the exclusion area compared to the control area (Fig. 4), but that the other small scavengers in the study area (stone marten and common genet) did not increase their consumption in the same way. The Egyptian mongoose is an opportunistic predator and used rabbit carcasses with a higher frequency than these other small carnivores which could be more focused on other food resources (Santos et al. 2007; Ferreras et al. 2011). The Egyptian mongoose is also a diurnal predator and can perhaps detect carrion more quickly owing to carrion odor increases during the warmer daylight hours during the winter period, when the study was mainly carried out (Turner et al. 2017; Tobajas et al. (in press). For these reasons, our prediction 3, that other singular opportunistic species would be favored by the removal of larger dominant scavengers, was confirmed by the significant increase in the scavenging activity of Egyptian mongoose. However, the increase in mongoose scavenging could not compensate for the reduction in carrion consumption by its two main competitors in the study area, the red fox and the European badger (Table 1). Red foxes have been described as facultative predators of rabbits, their main food resource when they are abundant (Delibes-Mateos et al. 2008) and have also been observed scavenging efficiently on rabbit carcasses and other carrion types in the Iberian peninsula (Tobajas et al. 2020a, under review). Similarly, while European badgers have been reported scavenging rabbit carcasses (Tobajas et al. 2020a), they usually predate mainly young rabbits inside burrows rather than taking adult rabbits above ground (Martín et al. 1995; Fedriani et al. 1998). However, our data showed that European badgers are important facultative scavengers on rabbit carcasses in Mediterranean woodlands.
The diminution of scavenger guild richness can produce a reduction in ecosystem function, and although there are compensatory effects, these may not be sufficient to compensate for these losses (Olson et al. 2012; Turner et al. 2017). Not only is the loss of richness important, but the identity and specific role of an individual scavenging species will determine the impact of its loss on the ecosystem (DeVault et al. 2011; Cunningham et al. 2018). Our data show that the loss or exclusion of larger scavengers produces a significant decrease in the overall efficiency of the scavenger community (Table 1, Figs. 2, 3), increasing the amount of carrion available in the environment for other opportunistic and non-targeted species and potentially increasing the probability of disease transmission (McColl et al. 2002; Markandya et al. 2008; Vidal et al. 2013). This unbalanced situation can benefit some species increasing its abundance and thereby lead to potentially negative effects on other species, such as prey (Cortés-Avizanda et al. 2009; Tobajas et al. (in press). However, the increased persistence time of carcasses enables colonization by a diverse community of carrionfeeding insects and increased microbial activity (DeVault et al. 2004; Muñoz-Lozano et al. 2019) providing increased food resources to species outside the mammalian scavenging community (Moreno-Opo and Margalida 2013).

A lack of top predators and the resulting ecosystem consequences have been widely studied (Elmhagen et al. 2010; Ripple and Beschta 2012; Jimenez et al. 2019), but there is little information on the effects on the facultative scavenger community (Wilson and Wolkovich 2011; Cunningham et al. 2018; Turner et al. 2020). Studies have mainly focused on the effects of the disappearance of obligate scavengers such as vultures, showing that their loss considerably reduces the efficiency of carrion removal (Sebastián-González et al. 2013; Hill et al. 2018), with a resultant loss of regulatory ecosystem services (e.g. the reduction of disease transmission, the management of carrion produced by livestock production and hunting activities, or the regulation of species that use carrion as subsidiary food sources, Markandya et al. 2008; Margalida and Colomer 2012; Oro et al. 2013; Morales-Reyes et al. 2017). However, the roles of facultative scavenger guilds such as mesocarnivores, and the effects arising from their alteration, are still not fully understood (Olson et al. 2012; Turner et al. 2020).

Predator control is a tool used in both game and conservation management (Reynolds and Tapper 1996; MorenoOpo et al. 2015). In the case of Mediterranean ecosystems, the red fox is one of the most controlled species in managed hunting estates, where it is considered one of the main threats to game species (Delibes-Mateos et al. 2013; Tobajas et al. 2020b). As this study shows (Table 1), the red fox is one of the main facultative scavenger species in Mediterranean ecosystems (Mateo-Tomás et al. 2015; Tobajas et al. (in press), so its continuous depletion can reduce the efficiency 
of rabbit carrion removal, this being especially important at times of high incidence of diseases such as viral hemorrhagic disease that can remain infectious in carcasses for several weeks after death (McColl et al. 2002; Henning et al. 2005). However, under natural conditions the removal of dominant mesopredators would probably trigger a numerical response in the small scavengers (Sinclair and Krebs 2002). Accordingly, its abundance may increase and partially compensate for the loss of dominant scavengers in the carrion consumption, thus reducing the observed effect in our exclusion study.

Unexpectedly, we observed that $5.8 \%$ of carrion was consumed by domestic dogs, showing that this species could be a locally important facultative scavenger (Butler and du Toit 2002; Forsyth et al. 2014). Subsidizing feral dog populations through carrion or discarded human food can lead to higher abundance of dogs and may have harmful effects on other species (Doherty et al. 2017; Tobajas et al. 2020c). An abundance of feral dogs increases competition between them and other facultative scavenger species, reducing the availability of carrion valuable to them (Butler and du Toit 2002; Stiegler et al. 2020). Increased feral dog populations may also have implications for predation pressure on vulnerable native species (Ritchie et al. 2014). However, our data suggest that scavenging by feral dogs is not common in the area and probably is owing to some free ranging individuals.

The type of exclusion fence used in this study could be useful to exclude large opportunistic scavenging species, such as red fox or wild boar, from supplementary feeding stations for vultures. The use of fences has been shown to benefit the conservation of vulture species (Moreno-Opo et al. 2010; Arrondo et al. 2015), some of which are threatened, by limiting access of unwanted opportunistic scavengers to food that is specifically placed in the field for vulture consumption (Moreno-Opo et al. 2012). This type of fencing could keep larger scavenging species away from vulture feeding stations while allowing the access to smaller species with lower carcass consumption, but benefit to some extent from this trophic resource.

In conclusion, our results show that when the facultative scavenger community in Mediterranean woodlands is altered, the efficiency of small carcass removal decreases and other opportunistic species such as the Egyptian mongoose can benefit from the sudden increase in carrion availability that was unavailable to larger competitor species. Despite this, the smaller facultative scavenger community could not compensate for the reduction in consumption of carrion by the dominant species without the presence of other species of obligate scavengers such as vultures (Olson et al. 2012; Hill et al. 2018). It is therefore important to understand the possible effects on the scavenger community and ecosystem functions of the loss of dominant scavenger species (Sebastián-González et al. 2020). The effects on carrion removal reported here could have substantial implications for controlling disease transmission, nutrient cycling, and ecosystem functioning.

Acknowledgements Two anonymous reviewers improved a previous version of this article. This study has been possible as a result of the CGL2013-40975-R and RTI2018-099609-B-C22 projects, from the I+D+I National Plan funded by the Spanish Ministry of Economy and Competitiveness and by the Ministry of Science, Innovation and Universities, and also of project (SBPLY-19-180501-000138) funded by the Junta de Comunidades de Castilla la Mancha. Jorge Tobajas is the recipient of an FPI PhD scholarship (BES-2014-068987) funded by the Spanish Ministry of Economy and Competitiveness.

Author contributions JT and AM conceived and designed the study. JT, ED, PF, RM conducted fieldwork. JT analyzed the data. JT, PF, RM and $\mathrm{AM}$ wrote the manuscript. RM, PF and AM got the funds.

Funding This study has been possible as a result of the CGL201340975-R and RTI2018-099609-B-C22 projects, from the I+D + I National Plan funded by the Spanish Ministry of Economy and Competitiveness and by the Ministry of Science, Innovation and Universities, and also of project (SBPLY-19-180501-000138) funded by the Junta de Comunidades de Castilla la Mancha. Jorge Tobajas is the recipient of an FPI PhD scholarship (BES-2014-068987) funded by the Spanish Ministry of Economy and Competitiveness. Open Access funding provided thanks to the CRUE-CSIC agreement with Springer Nature.

Data availability The datasets generated during and/or analyzed during the current study are available from the corresponding author on reasonable request.

\section{Declarations}

Conflict of interest Authors declare no conflicts of interests.

Ethical approval All applicable institutional and/or national guidelines for the care and use of animals were followed.

Consent to participate Not applicable.

Consent for publication Not applicable.

Open Access This article is licensed under a Creative Commons Attribution 4.0 International License, which permits use, sharing, adaptation, distribution and reproduction in any medium or format, as long as you give appropriate credit to the original author(s) and the source, provide a link to the Creative Commons licence, and indicate if changes were made. The images or other third party material in this article are included in the article's Creative Commons licence, unless indicated otherwise in a credit line to the material. If material is not included in the article's Creative Commons licence and your intended use is not permitted by statutory regulation or exceeds the permitted use, you will need to obtain permission directly from the copyright holder. To view a copy of this licence, visit http://creativecommons.org/licenses/by/4.0/. 


\section{References}

Amorós M, Gil-Sánchez JM, de las López-Pastor B, Moleón M (2020) Hyaenas and lions: how the largest African carnivores interact at carcasses. Oikos 129:1820-1832

Arrondo E, Cortés-Avizanda A, Donázar JA (2015) Temporally unpredictable supplementary feeding may benefit endangered scavengers. Ibis 157:648-651

Butler J, du Toit J (2002) Diet of free-ranging domestic dogs (Canis familiaris) in rural Zimbabwe: implications for wild scavengers on the periphery of wildlife reserves. Anim Conserv 5:29-37

Carrasco-Garcia R, Barroso P, Perez-Olivares J, Montoro V, Vicente J (2018) Consumption of big game remains by scavengers: a potential risk as regards disease transmission in central Spain. Front Vet Sci 5:4

Carricondo-Sanchez D, Samelius G, Odden M, Willebrand T (2016) Spatial and temporal variation in the distribution and abundance of red foxes in the tundra and taiga of northern Sweden. Eur J Wildl Res 62:211-218

Cortés-Avizanda A, Selva N, Carrete M, Donázar JA (2009) Effects of carrion resources on herbivore spatial distribution are mediated by facultative scavengers. Basic Appl Ecol 10:265-272

Cunningham CX, Johnson CN, Barmuta LA, Hollings T, Woehler EJ, Jones ME (2018) Top carnivore decline has cascading effects on scavengers and carrion persistence. Proc R Soc B 285:20181582

Delibes-Mateos M, De Simon JF, Villafuerte R, Ferreras P (2008) Feeding responses of the red fox (Vulpes vulpes) to different wild rabbit (Oryctolagus cuniculus) densities: a regional approach. Eur J Wildl Res 54:71-78

Delibes-Mateos M, Díaz-Fernández S, Ferreras P, Viñuela J, Arroyo B (2013) The role of economic and social factors driving predator control in small-game estates in central Spain. Ecol Soc 18:28

Descalzo E, Tobajas J, Villafuerte R, Mateo R, Ferreras P (2021) Plasticity in daily activity patterns of a key prey species in the Iberian Peninsula to reduce predation risk. Wildl Res. https://doi.org/10. 1071/WR20156

DeVault TL, Rhodes OE (2002) Identification of vertebrate scavengers of small mammal carcasses in a forested landscape. Acta Theriol 47:185-192

DeVault TL, Rhodes OE, Shivik JA (2003) Scavenging by vertebrates: behavioral, ecological, and evolutionary perspectives on an important energy transfer pathway in terrestrial ecosystems. Oikos 102:225-234

DeVault TL, Brisbin IL, Rhodes OE (2004) Factors influencing the acquisition of rodent carrion by vertebrate scavengers and decomposers. Can J Zool 82:502-509

DeVault TL, Olson ZH, Beasley JC, Rhodes OE (2011) Mesopredators dominate competition for carrion in an agricultural landscape. Basic Appl Ecol 12:268-274

DeVault TL, Beasley JC, Olson ZH, Moleón M, Carrete M, Margalida A, Sánchez-Zapata JA (2016) Ecosystem services provided by avian scavengers. In: Şekercioğlu ÇH, Wenny DG, Whelan CJ (eds) Why birds matter: avian ecological function and ecosystem services. University of Chicago Press, Chicago, IL, pp 235-270

Doherty TS, Dickman CR, Glen AS, Newsome TM, Nimmo DG, Ritchie EG, Vanak AT, Wirsing AJ (2017) The global impacts of domestic dogs on threatened vertebrates. Biol Conserv 210:56-59

Elmhagen B, Ludwig G, Rushton SP, Helle P, Lindén H (2010) Top predators, mesopredators and their prey: interference ecosystems along bioclimatic productivity gradients. J Anim Ecol 79:785-794

Fedriani JM, Ferreras P, Delibes M (1998) Dietary response of the Eurasian badger, Meles meles, to a decline of its main prey in the Doñana National Park. J Zool 245:214-218
Ferreras P, Travaini A, Zapata SC, Delibes M (2011) Short-term responses of mammalian carnivores to a sudden collapse of rabbits in Mediterranean Spain. Basic Appl Ecol 12:116-124

Forsyth DM, Woodford L, Moloney PD, Hampton JO, Woolnough AP, Tucker M (2014) How does a carnivore guild utilise a substantial but unpredictable anthropogenic food source? Scavenging on hunter-shot ungulate carcasses by wild dogs/dingoes, red foxes and feral cats in south-eastern Australia revealed by camera traps. PLOS ONE 9:e97937

Henning J, Meers J, Davies PR, Morris RS (2005) Survival of rabbit haemorrhagic disease virus (RHDV) in the environment. Epidemiol Infect 133:719-730

Hill JE, DeVault TL, Beasley JC, Rhodes OE, Belant JL (2018) Effects of vulture exclusion on carrion consumption by facultative scavengers. Ecol Evol 8:2518-2526

Jahren T, Odden M, Linnell JD, Panzacchi M (2020) The impact of human land use and landscape productivity on population dynamics of red fox in southeastern Norway. Mamm Res 65:503-516

Jimenez J, Nuñez-Arjona JC, Mougeot F, Ferreras P, González LM, García-Domínguez F, Muñoz-Igualada J, Palacios MJ, Pla S, Rueda C, Villaespesa F, Nájera F, Palomares F, López-Bao JV (2019) Restoring apex predators can reduce mesopredator abundances. Biol Conserv 238:108234

Margalida A, Colomer MA (2012) Modelling the effects of sanitary policies on European vulture conservation. Sci Rep 2:753

Margalida A, Colomer MA, Sanuy D (2011) Can wild ungulate carcasses provide enough biomass to maintain avian scavenger populations? An empirical assessment using a bio-inspired computational model. PLoS ONE 6:e20248

Markandya A, Taylor T, Longo A, Murty M, Murty S, Dhavala K (2008) Counting the cost of vulture decline-an appraisal of the human health and other benefits of vultures in India. Ecol Econ 67:194-204

Martín R, Rodríguez A, Delibes M (1995) Local feeding specialization by badgers (Meles meles) in a Mediterranean environment. Oecologia 101:45-50

Mateo-Tomás P, Olea PP, Moleón M, Vicente J, Botella F, Selva N, Viñuela J, Sánchez-Zapata JA (2015) From regional to global patterns in vertebrate scavenger communities subsidized by big game hunting. Divers Distrib 21:913-924

McColl KA, Morrissy CJ, Collins BJ, Westbury HA (2002) Persistence of rabbit haemorrhagic disease virus in decomposing rabbit carcasses. Aust Vet J 80:298-299

Moleón M, Sánchez-Zapata JA, Margalida A, Carrete M, OwenSmithDonázar NJA (2014) Humans and scavengers: evolution of interactions and ecosystem services. Bioscience 64:394-403

Monterroso P, Alves PC, Ferreras P (2014) Plasticity in circadian activity patterns of mesocarnivores in Southwestern Europe: implications for species coexistence. Behav Ecol Sociobiol 68:1403-1417

Monterroso P, Díaz-Ruiz F, Lukacs PM, Alves PC, Ferreras P (2020) Ecological traits and the spatial structure of competitive coexistence among carnivores. Ecology 101:e03059

Morales-Reyes Z, Sánchez-Zapata JA, Sebastián-González E, Botella F, Carrete M, Moleón M (2017) Scavenging efficiency and red fox abundance in Mediterranean mountains with and without vultures. Acta Oecol 79:81-88

Moreno S, Villafuerte R, Cabezas S, Lombardi L (2004) Wild rabbit restocking for predator conservation in Spain. Biol Conserv 118:183-193

Moreno-Opo R, Margalida A (2013) Carcasses provide resources not exclusively to scavengers: patterns of carrion exploitation by passerine birds. Ecosphere 4:105

Moreno-Opo R, Margalida A, Arredondo A, Guil F, Martín M, Higuero R, Soria C, Guzmán J (2010) Factors influencing the presence of the cinereous vulture Aegypius monachus at carcasses: food 
preferences and implications for the management of supplementary feeding sites. Wildl Biol 16:25-34

Moreno-Opo R, Margalida A, García F, Arredondo A, Rodríguez C, González LM (2012) Linking sanitary and ecological requirements in the management of avian scavengers: effectiveness of fencing against mammals in supplementary feeding sites. Biodivers Conserv 21:1673-1685

Moreno-Opo R, Afonso I, Jimenez J, Fernandez-Olalla M, Canut J, Garcia-Ferré D, Piqué J, García F, Roig J, Muñoz-Igualada J, González LM, López-Bao JV (2015) Is it necessary managing carnivores to reverse the decline of endangered prey species? Insights from a removal experiment of mesocarnivores to benefit demographic parameters of the Pyrenean capercaillie. PLoS ONE 10:e0139837

Moreno-Opo R, Trujillano A, Margalida A (2016) Behavioural coexistence and feeding efficiency drive niche partitioning at carcasses within the guild of European avian scavengers. Behav Ecol 27:1041-1052

Muñoz-Lozano C, Martín-Vega D, Martínez-Carrasco C, SánchezZapata JA, Morales-Reyes Z, González M, Moleón M (2019) Avoidance of carnivore carcasses by vertebrate scavengers enables colonization by a diverse community of carrion insects. PLoS ONE 14:e0221890

Ogada D, Torchin M, Kinnaird M, Ezenwa V (2012) Effects of vulture declines on facultative scavengers and potential implications for mammalian disease transmission. Conserv Biol 26:453-460

Olson ZH, Beasley JC, DeVault TL, Rhodes OE (2012) Scavenger community response to the removal of a dominant scavenger. Oikos 121:77-84

Oro D, Genovart M, Tavecchia G, Fowler MS, Martínez-Abraín A (2013) Ecological and evolutionary implications of food subsidies from humans. Ecol Lett 16:1501-1514

Pardo-Barquín E, Mateo-Tomás P, Olea PP (2019) Habitat characteristics from local to landscape scales combine to shape vertebrate scavenging communities. Basic Appl Ecol 34:126-139

R Core Team (2020) R: a language and environment for statistical computing. R Foundation for Statistical Computing, Vienna, Austria

Reynolds JC, Tapper SC (1996) Control of mammalian predators in game management and conservation. Mamm Rev 26:127-156

Ripple WJ, Beschta RL (2012) Trophic cascades in Yellowstone: the first 15years after wolf reintroduction. Biol Conserv 145:205-213

Ritchie EG, Dickman CR, Letnic M, Vanak AT, Gommper M (2014) Dogs as predators and trophic regulators. In: Gomper ME (ed) Free-ranging dogs and wildlife conservation. Oxford University Press, Oxford, UK, pp 55-68

Santos MJ, Pinto BM, Santos-Reis M (2007) Trophic niche partitioning between two native and two exotic carnivores in SW Portugal. Web Ecol 7:53-62

Sebastián-González E, Sánchez-Zapata JA, Donázar JA, Selva N, Cortés-Avizanda A, Hiraldo F, Blázquez M, Botella F, Moleón M (2013) Interactive effects of obligate scavengers and scavenger community richness on lagomorph carcass consumption patterns. Ibis $155: 881-885$
Sebastián-González E, Moleón M, Gibert JP, Botella F, Mateo-Tomás P, Olea PP, Guimarães PR, Sánchez-Zapata JA (2016) Nested species-rich networks of scavenging vertebrates support high levels of interspecific competition. Ecology 97:95-105

Sebastián-González E, Morales-Reyes Z, Botella F, Naves-Alegre L, Pérez-García JM et al (2020) Network structure of vertebrate scavenger assemblages at the global scale: drivers and ecosystem functioning implications. Ecography 43:1-13

Sinclair ARE, Krebs CJ (2002) Complex numerical responses to topdown and bottom-up processes in vertebrate populations. Phil Trans R Soc B 357:1221-1231

Stiegler J, von Hoermann C, Müller J, Benbow ME, Heurich M (2020) Carcass provisioning for scavenger conservation in a temperate forest ecosystem. Ecosphere 11:e03063

Swihart RK, Gehring TM, Kolozsvary MB, Nupp TE (2003) Responses of 'resistant' vertebrates to habitat loss and fragmentation: the importance of niche breadth and range boundaries. Divers Distrib 9:1-18

Tobajas J, Oliva-Vidal P, Piqué J, Afonso-Jordana I, García-Ferré D, Moreno-Opo R, Margalida A (in press) Scavenging patterns of generalist predators in forested areas: the potential implications of the increase in carrion availability on a threatened Capercaillie population. Anim Conserv

Tobajas J, Descalzo E, Mateo R, Ferreras P (2020a) Reducing nest predation of ground-nesting birds through conditioned food aversion. Biol Conserv 242:108405

Tobajas J, Descalzo E, Villafuerte R, Jimenez J, Mateo R, Ferreras P (2020b) Conditioned odor aversion as a tool for reducing postrelease predation during animal translocations. Anim Conserv. https://doi.org/10.1111/acv.12643

Tobajas J, Jiménez J, Sánchez-Rojas G (2020c) Factors affecting the abundance of Peters's squirrel, Sciurus oculatus, in a population of Central Mexico. Rev Mex Biodivers 91:913064

Turner K, Abernethy E, Conner LM, Rhodes OE, Beasley JC (2017) Abiotic and biotic factors modulate carrion fate and vertebrate scavenging communities. Ecology 98:2413-2424

Turner KL, Conner LM, Beasley JC (2020) Effect of mammalian mesopredator exclusion on vertebrate scavenging communities. Sci Rep 10:1-9

Vidal D, Anza I, Taggart MA, Pérez-Ramírez E, Crespo E, Hofle U, Mateo R (2013) Environmental factors influencing the prevalence of a Clostridium botulinum type C/D mosaic strain in nonpermanent Mediterranean wetlands. Appl Environ Microbiol 9:4264-4271

Wilson EE, Wolkovich EM (2011) Scavenging: how carnivores and carrion structure communities. Trends Ecol Evol 26:129-135

Publisher's Note Springer Nature remains neutral with regard to jurisdictional claims in published maps and institutional affiliations. 